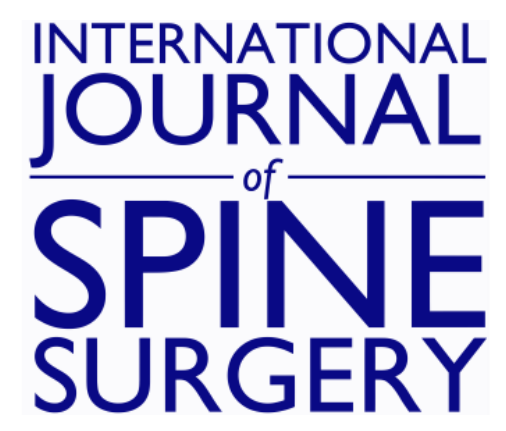

\title{
Magnetic Resonance Imaging of the Cervical Spine Under-Represents Sagittal Plane Deformity in Degenerative Myelopathy Patients
}

Douglas S. Weinberg, Arunit J. Chugh, Jeremy J. Gebhart and Jason D. Eubanks

Int J Spine Surg 2016, 10 ()

doi: https://doi.org/10.14444/3032

http://ijssurgery.com/content/10/32

This information is current as of April 26, 2023.

Email Alerts Receive free email-alerts when new articles cite this article. Sign up at:

http://ijssurgery.com/alerts

The International Journal of Sphine Surgerbittp://ijssurgery.com/ by guest on April 26, 2 2397 Waterbury Circle, Suite 1,

Aurora, IL 60504, Phone: +1-630-375-1432

(C) 2016 ISASS. All Rights Reserved. 


\section{Magnetic Resonance Imaging of the Cervical Spine Under-Represents Sagittal Plane Deformity in Degenerative Myelopathy Patients}

Douglas S. Weinberg, MD,1 Arunit J. Chugh, MD,2 Jeremy J. Gebhart, MD,1 Jason D. Eubanks, MD1

${ }_{1}^{1}$ epartment of Orthopaedic Surgery, Case Western Reserve University, Cleveland, Ohio, ${ }^{2}$ Department of Neurosurgery, Case Western Reserve University, School of Medicine, Cleveland, Ohio

\section{Abstract}

Background

In treating patients with cervical myelopathy, surgical approach may be dictated by sagittal balance, highlighting the need for accurate pre-operative assessment. Magnetic Resonance Imaging (MRI) is widely-recognized for its utility in the diagnosis and surgical planning of cervical myelopathy. Plain radiographs (X-rays) are a reliable tool to assess bony alignment. However, they may not always be included in standard pre-operative evaluation, especially in an era of restricted payer-environments. Failure to appropriately acknowledge a patients' preoperative kyphotic deformity may cause the surgeon to choose a posterior-only approach, which would provide suboptimal sagittal plane correction and decompression of anterior pathology.

Methods

101 patients with cervical myelopathy with MRI and plain radiographs were identified. Cervical lordosis and kyphosis were measured using the Cobb method on standing lateral x-ray and sagittal T2-weighted MRI. CI (Ishihara) was also measured on standing lateral x-ray, and sagittal T2-weighted MRI. Bland-Altman plots were generated and used to compare subtle differences in measurement techniques and modalities. Odom's criteria were recorded.

\section{Results}

The average difference between plain radiograph and MRI measurements for curvature angle was $3.5 \pm 7.2$ degrees $(\mathrm{p}<0.001)$, and the average difference between plain radiograph and MRI measurements for curvature index was $1.5 \pm 5.9$ degrees $(\mathrm{p}=0.015)$.

\section{Conclusions}

MRI may under-represent the respective sagittal plane deformity in patients with degenerative cervical myelopathy.

\section{Clinical Relevance}

We would recommend the use of standing $\mathrm{x}$-rays when considering surgical planning in all myelopathy patients.

This manuscript was reviewed and approved by an institutional review board. Informed consent was not obtained because patient specific identifying information was not used. It was performed in accordance with the ethical standards laid down in the 1964 Declaration of Helsinki and its later amendments.

KEYWORDS: CERVICAL MYELOPATHY, X-RAY, SAGITTAL BALANCE, KYPHOSIS, CURVATURE INDEX

\section{Introduction}

Proper evaluation of sagittal balance is of paramount importance during the management of cervical myelopathy. While the clinical diagnosis is based on history and physical examination, plain radiographs (X-rays) and Magnetic Resonance Imaging (MRI) represent an important part of evaluation and surgical planning. Surgical decompression and stabilization remains the mainstay of treatment for patients 
with severe clinical symptoms. During pre-operative planning, the surgeon must make important decisions regarding surgical approach, stabilization, and the restoration of sagittal balance. The combination of these factors has profound implications for the improvement of neurological recovery following decompression. ${ }^{1-3}$

It has been well-established that patients who present with severe kyphosis deformity pre-operatively have suboptimal outcomes when anterior pathology is not appropriately decompressed. Many authors have suggested that a kyphosis of more than 10 degrees necessitates an anterior approach (or combined approach) to adequately reduce cord tensioning. ${ }^{4-7} \mathrm{Simi}-$ larly, the development of post-laminectomy kyphosis can become accelerated when decompression is performed without fusion in the presence of pre-existing deformity.

Upright plain radiographs are a reliable tool to assess bony alignment and are considered by most authors the gold standard for evaluating cervical lordosis or kyphosis. However, with the increasing use of MRI, it may not be a part of certain practitioner's standard pre-operative evaluation. Furthermore, in an increasingly restricted payer environment where radiographs and MRI are often being limited, knowing the value of each in the surgical planning process is especially relevant at the present time.

We therefore determined it would be clinically prudent to perform a review comparing how cervical curvature angle (lordosis or kyphosis) ${ }^{7}$ and cervical curvature index (Ishihara) ${ }^{8}$ varied between plain radiograph and MRI. The purpose of this study was to compare various measures of sagittal balance on plain radiograph versus MRI. We hypothesized that the magnitude of sagittal plane deformity would be greater on plain radiograph when compared to MRI.

\section{Materials and Methods}

Following Institutional Review Board approval, a series of 151 patients whose history, physical exam, and imaging were consistent with the diagnosis of cervical myelopathy were retrospectively reviewed. ${ }^{9,10}$ All patients were from the practice of a single, fellowship-trained spine surgeon and were evaluated between May 2009 and October 2013. Patients were included if they had high-quality plain radiographs of the lateral cervical spine in a standing, upright position, and $\mathrm{T} 1$ and $\mathrm{T} 2$-weighted magnetic resonance imaging (MRI) of the cervical spine available for review. Patients were excluded for having incomplete radiographic records or incomplete visualization of C7 on plain radiograph (20), prior spine surgery or trauma (18), more than 3 months duration between plain film and MRI measurements (10), or severe coronal plane deformities (2). In total, 50 patients were excluded, and 101 unique patients were enrolled for primary analysis. Patient demographic information was also available for review. Odom's criteria were recorded postoperatively.

\section{Measuring Curvature Angle and Curvature Index (Ishihara)}

The curvature angle was measured on plain radiographs of the lateral cervical spine using the fourline Cobb technique, from the base of $\mathrm{C} 2$ to the base of C7 (Figure 1). ${ }^{11,12}$ A straight line was drawn along the inferior aspect of each vertebral end plate. A line was drawn perpendicular to both segments. Curvature angle was measured on the mid-sagittal slice of T2-weighted MRI (Figure 2).

Curvature index was measured on plain film of the lateral cervical spine using the Ishihara technique (Figure 3). ${ }^{8}$ A straight line was drawn from the posterior-inferior aspect of $\mathrm{C} 2$ to the posteriorinferior aspect of $\mathrm{C} 7(\mathrm{AB})$. The distances $\left(\mathrm{d}_{1-4}\right)$ between the posterior-inferior aspects of $\mathrm{C} 3, \mathrm{C} 4, \mathrm{C} 5$, and $\mathrm{C} 6$ to the orthogonal intersection of the line from $\mathrm{C} 2$ to $\mathrm{C} 7$ were measured. The curvature index was calculated:

\section{$\frac{d 1+d 2+d 3+d 4}{A B} \times 100=$ Curvature Index}

These measurements were repeated on the midsagittal slice of T2-weighted MRI (Figure 4).

To ensure consistency, all measurements were performed by a single author, and two other authors provided inter-observer reliability for all measurements on 25 individuals. One of the authors assessed intra- 
observer reliability with 21-day separation between measurements. All measurements were reported to the nearest 0.1 degree. Cervical lordosis was defined as either a positive curvature angle or curvature index on plain radiograph, respective to each analysis.

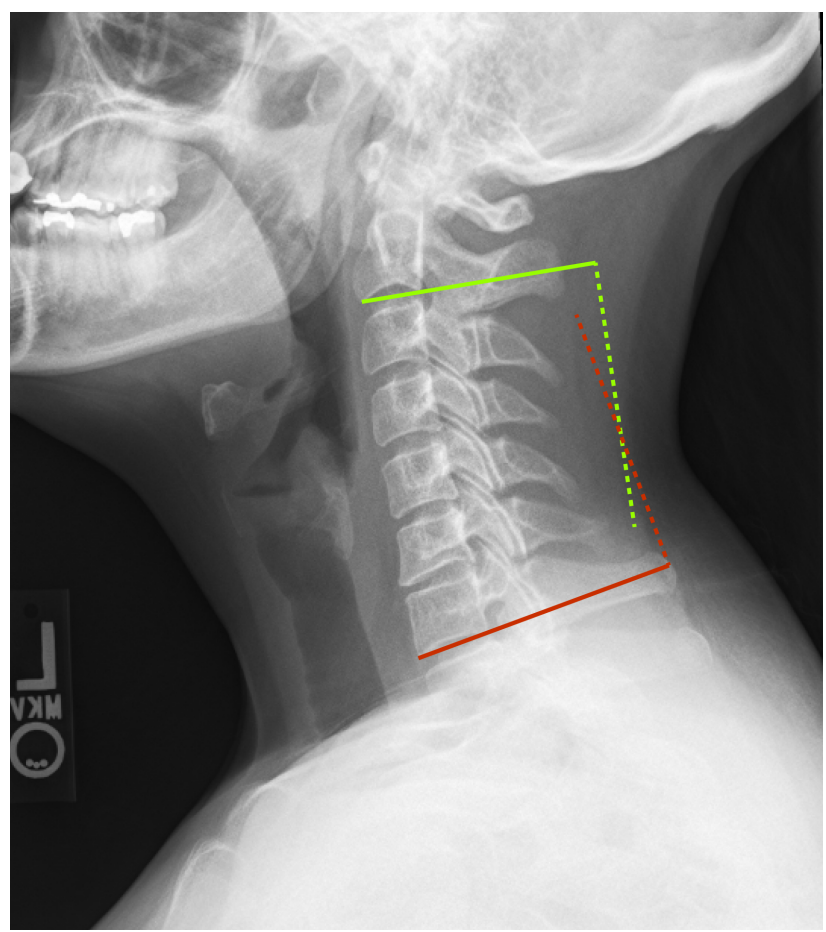

Fig. 1. Curvature angle measured using the Cobb technique on plain radiograph. A line was placed along the inferior aspect of $C 2$ (yellow solid line), and a perpendicular line (yellow dashed) was drawn. A line was placed along the inferior aspect of $\mathrm{C} 7$ (red line), and a perpendicular line (yellow dashed) was then drawn. The acute angle subtended between the two crossing lines is the curvature angle. In this example the measurement was 12.2 degrees of lordosis.

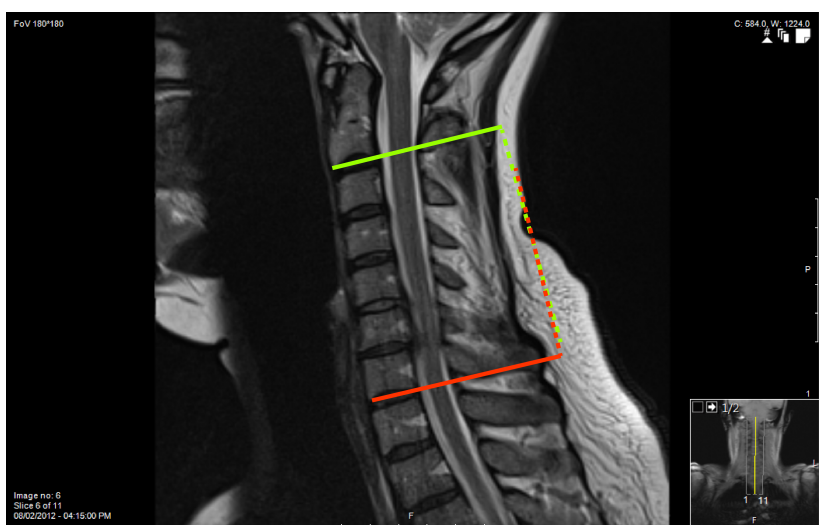

Fig. 2. Curvature angle measured using the Cobb technique on MR, on the same individual seen in Figure 1. A line was placed along the inferior aspect of C2 (solid line), and a perpendicular line (yellow dashed) was drawn. A line was placed along the inferior aspect of $\mathrm{C} 7$ (red line), and a perpendicular line (yellow dashed) was then drawn. The acute angle subtended between the two crossing lines is the curvature angle. In this example the measurement was 1.6 degrees of kyphosis, notably different than the measurement performed on plain radiograph.
Cervical kyphosis was defined as curvature angle or curvature index less than zero on plain radiograph,

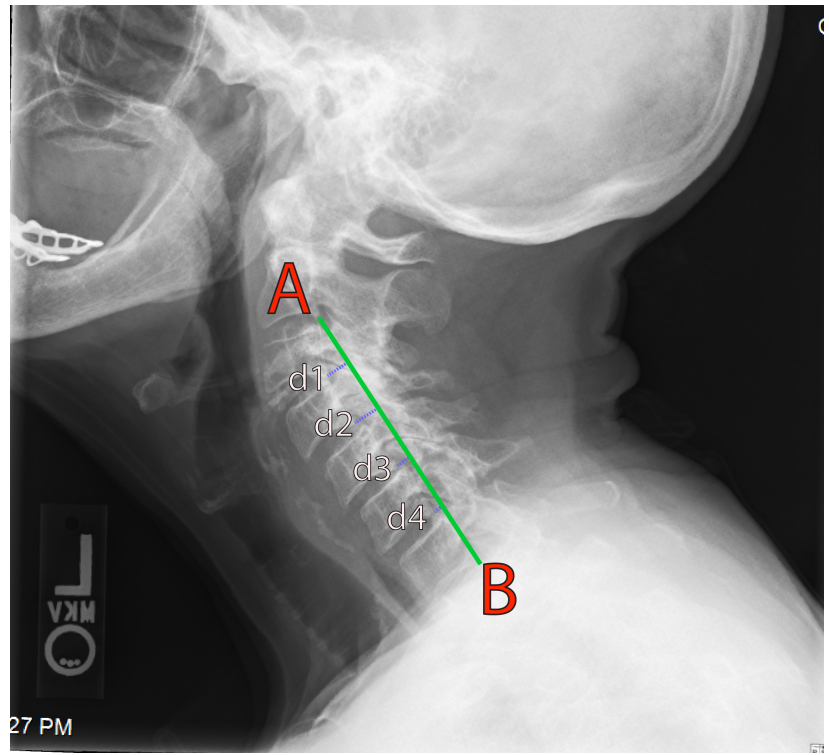

Fig. 3. Curvature index (Ishihara) measured on plain radiograph. A line is connected between the most posterior-inferior portion of $C 2(A)$ and the most posterior-inferior portion of $C 7$ (B). The distance of line (AB) was recorded. The distances between the posterior-inferior aspects of $\mathrm{C} 3, \mathrm{C} 4$, $C 5$, and $\mathrm{C} 6$ to the orthogonal intersection of the line from $\mathrm{C} 2$ to $\mathrm{C} 7$ was calculated $\left(d_{1-4}\right)$. The curvature index was calculated:

\section{$\frac{d 1+d 2+d 3+d 4}{A B} \times 100=$ Curvature Index}

In this example the measurement was 31.1

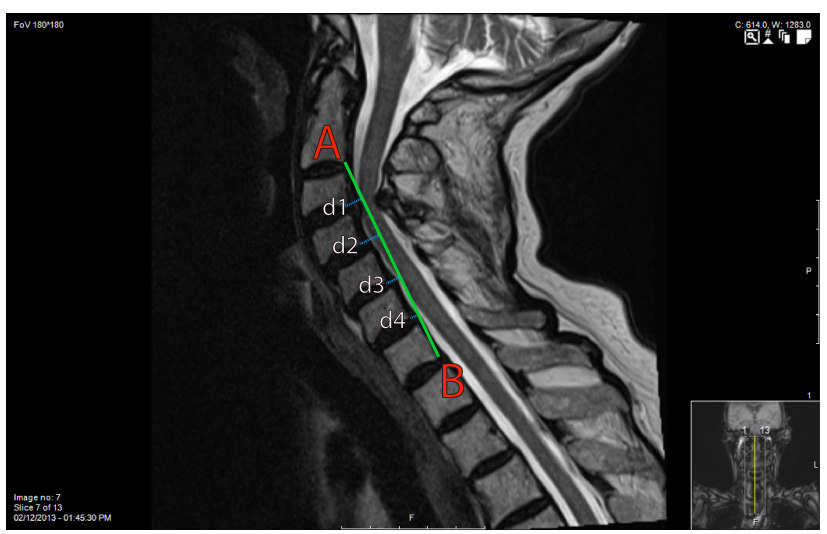

Fig. 4. Curvature index (Ishihara) measured on MRI, on the same individual seen in Figure 3. A line is connected between the most posterior-inferior portion of $C 2(A)$ and the most posterior-inferior portion of $C 7(B)$. The distance of line $(A B)$ was recorded. The distances between the posterior-inferior aspects of $\mathrm{C} 3, \mathrm{C} 4, \mathrm{C} 5$, and $\mathrm{C} 6$ to the orthogonal intersection of the line from $C 2$ to $C 7$ was calculated $\left(d_{1-4}\right)$. The curvature index was calculated:

$$
\frac{d 1+d 2+d 3+d 4}{A B} \times 100=\text { Curvature Index }
$$

In this example the measurement was 30.9 
respective to each analysis. For each measurement, patients with cervical kyphosis and lordosis were compared separately. Measurements were made on a GE Centricity PACS workstation (GE Healthcare, Wauwatosa, Wisconsin, USA).

\section{Comparison of Measurements Techniques}

Curvature index was subsequently expressed in degrees, as has been suggested for comparison to other measurements. ${ }^{8}$ To compare measurements across imaging modalities, the Bland-Altman method for assessing agreement between two methods of clinical measurement was used. ${ }^{13}$ This technique is designed to compare two measurement techniques thought to represent the same value across different modalities, and allows for identification of fixed versus inconsistent biases. It has been described as an ideal statistical analysis to determine if two clinical measurements agree with one another. ${ }^{13-17}$ It has previously been used to assess the reliability of the powers ratio between plain film and computed tomography, ${ }^{18}$ Modic changes between T1 versus T2-weighted imaging ${ }^{19}$ pelvic tilt measurements, ${ }^{20}$ among numerous other applications. Its fundamental computation involves taking the average value of two matched pairs of measurements, and then comparing to the difference between each set of measurement values. The results are generally interpreted informally, with emphasis on any clinical, rather than statistical, differences that may exist. ${ }^{13}$

\section{Statistical Methods}

All data was analyzed for skewness and kurtosis. Comparisons between the differences of continuous variables were performed with t-tests. Correlations between continuous variables were performed with the Pearson's correlation coefficient or Spearman's rank correlation coefficient, where parametrically appropriate. Inter- and intra-observer measurement reliability was assessed with the intraclass correlation coefficient. Bland-Altman plots were generated. All data analyses was performed with the SPSS 22.0 software package (IBM Corporation, Armonk, NY). Significance was set at $\mathrm{p} \leq 0.05$

\section{Results}

The mean and standard deviation of patient age and was $59 \pm 14$ years. There were 49 males $(49 \%)$ and 52 females. Inter-observer reliabilities for measurements of curvature angle were 0.84 and 0.92 on plain radiograph and MRI, respectively. Intra-observer reliabilities were 0.88 and 0.92 on plain radiograph and MRI, respectively. Inter-observer reliabilities for measurements of curvature index were 0.77 and 0.84 on plain radiograph and MRI, respectively, and intraobserver reliabilities were 0.80 and 0.90 , on plain radiograph and MRI, respectively. All measurements showed excellent reliability $(>0.75)$ as defined by Fleiss et al. for agreement of like measurements of continuous variables. $^{21}$

The average curvature angle was $9.8 \pm 13.8$ degrees on plain radiograph, and 6.2 \pm 12.7 degrees on MRI. There were 25 patients with kyphosis deformity using this technique (curvature angle less than 0 degrees on plain radiograph. The average curvature index (Ishihara) was 5.4 \pm 13.6 degrees on plain radiograph, and $4.0 \pm 12.8$ degrees on MRI. There were 30 patients with kyphosis deformity using this technique (curvature index less than 0 degree on plain radiograph). Individual correlations between measurements techniques were calculated (Table 1), and were above 0.8 for comparisons between like measurements and like techniques. One-sample statistics showed an average difference of $3.5 \pm 7.2$ degrees between plain radiograph and MRI measurements for curvature angle $(\mathrm{p}<0.001)$, and an average difference of $1.5 \pm 5.9$ degrees between plain radiograph and MRI measurements for curvature index $(p=0.015)$.

There were no differences in post-operative Odom's criteria based on curvature angle, measured on plain radiograph or MRI, or based on curvature index measured on plain radiograph or MRI ( $p>0.05$ for all).

Table 1. Individual Correlations between Measurements.
\begin{tabular}{|l|r|r|r|r|}
\hline CA X-ray & CA MRI & CI X-ray & CI MRI \\
\hline CA X-ray & --- & 0.853 & 0.839 & 0.790 \\
\hline CA MRI & 0.853 & --- & 0.757 & 0.814 \\
\hline CI X-ray & 0.839 & 0.757 & --- & 0.899 \\
\hline CI MRI & 0.790 & 0.814 & 0.899 & -- \\
\hline CA: Curvature Angle, Cl: Curvature Index & & \\
All correlations were statistically significant $(p<0.05)$
\end{tabular}


Bland-Altman plots were generated for comparisons between curvature angle measurements on plain radiograph and MRI (Figure 5) and comparisons between curvature index measurements on plain radiograph and MRI (Figure 6). Average (solid lines) and 95\% confidence intervals (dashed) of the differences in measuring technique were created.

\section{Discussion}

Cervical myelopathy is the most common cause of spinal cord dysfunction among adults and usually results from degenerative spondylosis. ${ }^{22}$ Brain et al. first described a progressive clinical syndrome of spinal cord compression that can present with a wide spectrum of signs and symptoms. ${ }^{23}$ Classic literature described a characteristic presentation of paresthesias, neck pain, weakness, subtle changes in gait and locomotion, and overall clumsiness. ${ }^{24-26}$ Cervical myelopathy is a progressive disorder and typically does not improve; most patients experience a slow deterioration over time. The diagnosis is based on history and physical examination, however, Magnetic
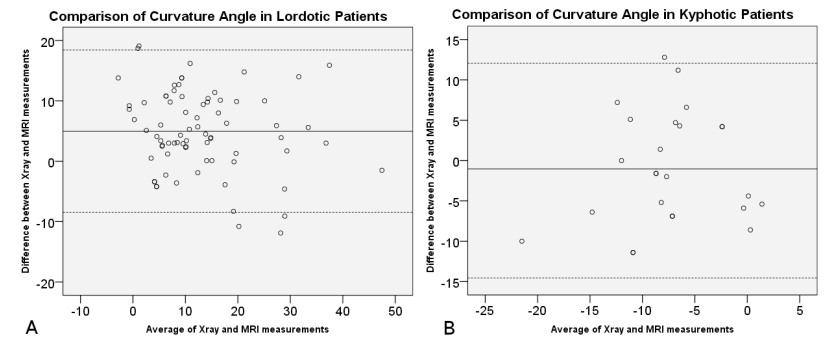

Fig. 5. Bland-Altman plots of comparisons of curvature angle in lordotic (a) and kyphotic (b) patients. The average between pairs of measurements are plotted against their difference. The solid line indicates mean bias (average difference), and the dotted lines are limits of agreement ( $95 \%$ confidence limit lines).
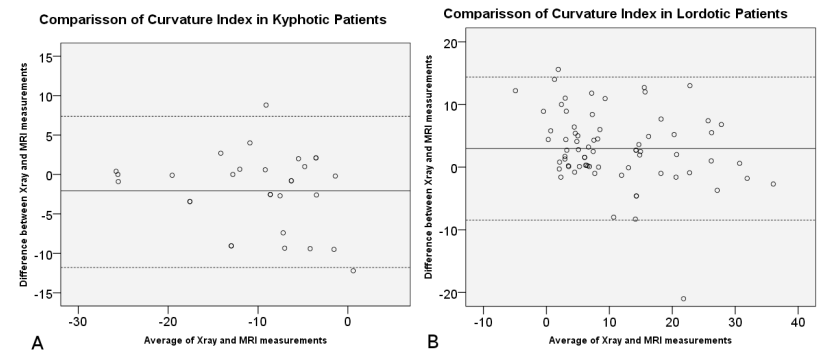

Fig. 6. Bland-Altman plots of comparisons of curvature index in lordotic (a) and kyphotic (b) patients. The average between pairs of measurements are plotted against their difference. The solid line indicates mean bias (average difference), and the dotted lines are limits of agreement ( $95 \%$ confidence limit lines).
Resonance Imaging (MRI) has an important role in diagnostic workup and is useful for determining the degree of compression of the spinal cord and nerve roots. ${ }^{9}$ Some authors have suggested using it as a means to quantify sagittal balance of the cervical spine, which has traditionally been performed on plain radiograph. ${ }^{27}$ However, to our knowledge, there have been no reports in the literature comparing cervical sagittal alignment measured using standing, upright plain radiographs versus recumbently positioned MRI. Therefore, we designed a radiographic study designed to evaluate the differences in sagittal spine alignment in a patient population with cervical myelopathy.

Our findings suggest that despite strong correlations between all measurements used in these analyses, there still existed considerable difference among measurement modalities. Some have suggested that a correlation above 0.6 among measurement techniques constitutes "good" agreement for clinical practice ${ }^{28}$ although most modern authors agree that a more thorough comparative analysis is required to see subtle differences. ${ }^{29}$ The Bland-Altman plots used in this paper highlight this concept and show that despite strong correlations between radiographic and MRI measurements of curvature angle (Cobb), there was a statistically significant difference between them for patients with both kyphotic and lordotic deformities. Moreover, the relatively large standard deviations suggest that these differences are not consistent among individuals. The average discrepancy between modalities has the potential to represent a clinically significant effect. Moreover, the dispersion of data in these plots suggests there is no fixed bias between the two measurements. ${ }^{13,16}$

In other words, one cannot simply assume that radiographic measurements are a constant number of degrees different than those found on MRI. This is likely due to the development of rigid versus flexible kyphosis, age-related changes of the disc space and posterior elements, and patient-specific parameters. ${ }^{30-32}$ Similarly, smaller, but still significant differences in curvature index (Ishihara) between plain radiograph and MRI existed making their interchangeable use impossible. Given that even small changes in sagittal balance have important implications in cervi- 
cal myelopathy, the accurate assessment of such is critical. Lateral radiographs have the strongest literature precedent for such, and the results of this study would suggest that measuring sagittal balance on MRI is inadequate for quantifying cervical lordosis or kyphosis as traditionally defined. ${ }^{33-35}$ It is possible, however, that there exist future applications for these measurements.

The results of this study are consistent with the anecdotal observations of spine surgeons at our institution and elsewhere. The increasing use of MRI has caused some non-spine care providers and third party payers to question the role of traditional radiography, although this study suggests that proper evaluation of sagittal balance - of critical importance during the evaluation of cervical myelopathy-can only be performed on plain radiograph.

It is likely that major differences between radiographic and MRI measurements are related to patientpositioning. Traditionally, sagittal balance has been evaluated using lateral plain radiographs. This places the cervical spine in a weight-bearing and loadsharing position. Radiographs performed in the upright position cause gravity to stress the anterior and posterior ligaments, which may be crucial for establishing alignment. ${ }^{36-38}$ While no differences in postoperative outcomes were notes based on any imaging parameter, this result is likely confounded by the fact that surgical planning was dictated by sagittal balance. However, post-operatively, there were no differences in clinical outcomes, suggesting that most data is needed to determine the appropriate application going forward.

Curvature index (Ishihara) has been proposed as an alternative means to quantify sagittal alignment of the cervical spine. While computing its individual measurements may be too time-consuming for routine clinical application, proponents of its use have suggested that it is less influenced by small changes in the endplates of $\mathrm{C} 2$ and $\mathrm{C}$, provides a more accurate global assessment of sagittal balance, with equal emphasis on each cervical unit. It may also offer advantages in quantifying sagittal balance in spines with coronal plane deformities. ${ }^{8,39}$ A previous mathematical model by Takeshita et al. showed extremely high correlations between curvature index and cervical curvature angle on MRI. ${ }^{8}$ This study confirms this relationship and validates those results, although the correlations in this experiment were slightly lower than reported in conceptual modeling. This is to be expected as inherent measurement errors are introduced during clinical application and were not accounted for in mathematical modeling. While comparisons of curvature index (Ishihara) between plain radiograph and MRI had much smaller differences than those of curvature angle (Cobb), these differences were still significant and with non-fixed variability, as shown on Bland-Altman plots. This makes them too dissimilar to be considered congruent.

It has been suggested that the Cobb angle method for determining cervical lordosis underrepresents cervical lordosis when measured from $\mathrm{C} 2-\mathrm{C} 7$ and overestimates lordosis when measured from C1-C7. Alternative methods to assess sagittal balance include the Harrison posterior tangent method, ${ }^{40}$ and Jackson physiological stress lines. ${ }^{7}$ The Cobb method was chosen for use in this study given its good inter- and intra-relator reliability in previous studies, and is simple, effective application in clinical use..$^{41,42}$ Measurements of curvature index (Ishihara) ${ }^{8}$ have been proposed as an alternative technique, although there are only limited other studies available validating its use. $^{39,43-45}$

This study has important limitations. Functional outcomes before or after surgery were not included in these analyses. This introduces a similar problem found in other radiographic studies. However, previous authors have well-established the relationship between kyphosis deformity and cervical myelopathy, and all patients with significant deformity in this series were managed with either a combined anterior/ posterior approach or an anterior-only approach. Additionally, this study used only two measurement techniques to quantify cervical kyphosis. As discussed above, previous authors have shown certain differences exist between techniques, although the C2 Cobb method may be the most readily applicable in clinical practice. ${ }^{7}$ This study assumes that differences in measurement values were due to differences in recumbent patient positioning and imaging output, although other factors such as rotation, lateral 
bending, magnification, and resolution may have contributed. Additionally, this study only included patients with cervical myelopathy to assess sagittal balance; however, this cohort was chosen given the important emphasis this has during their treatment course. Nonetheless, it is possible that patients with other pathologies, such as radiculopathy, or those with normal spines, may have produced different results. While this experiment did not evaluate upright MRI, we think this represents an important and fertile area for future research.

In conclusion, our radiographic review of $101 \mathrm{pa}-$ tients with cervical myelopathy showed that important differences exist in the measurement of sagittal balance on plain radiograph and MRI when using a variety of techniques. Standing, upright radiographs of the lateral cervical spine has been the goldstandard for evaluating cervical lordosis or kyphosis. These measurements cannot be reproduced or emulated using other modalities despite the strong correlations between techniques and modalities.

\section{References}

1. Chen J, Liu Z, Zhong G, Qian L, Li Z, Chen B, et al. Surgical treatment for cervical spondylotic myelopathy in elderly patients: A retrospective study. Clinical Neurology and Neurosurgery. 2015 5//;132(0):47-51.http://dx.doi.org/10.1016/ j.clineuro.2015.02.012

2. Hirabayashi K, Miyakawa J, Satomi K, Maruyama T, Wakano K. OPERATIVE RESULTS AND POSTOPERATIVE PROGRESSION OF OSSIFICATION AMONG PATIENTS WITH OSSIFICATION OF CERVICAL POSTERIOR LONGITUDINAL LIGAMENT. Spine.

1981;6(4):354-64.10.1097/

00007632-198107000-00005

3. Hirabayashi K, Watanabe K, Wakano K, Suzuki N, Satomi K, Ishii Y. EXPANSIVE OPEN-DOOR LAMINOPLASTY FOR CERVICAL SPINAL STENOTIC MYELOPATHY. Spine.

1983;8(7):693-9.10.1097/

00007632-198310000-00003

4. Acosta FL, Jr., Aryan HE, Chou D, Ames CP. Long-term biomechanical stability and clinical im- provement after extended multilevel corpectomy and circumferential reconstruction of the cervical spine using titanium mesh cages. Journal of Spinal Disorders \& Techniques. 2008 May;21(3):165-74.10.1097/ BSD.0b013e3180654205

5. Fehlings MG, Gray R. Importance of sagittal balance in determining the outcome of anterior versus posterior surgery for cervical spondylotic myelopathy. Journal of Neurosurgery-Spine. 2009 Nov;11(5):518-9.10.3171/2009.5.spine09182 6. O'Shaughnessy BA, Liu JC, Hsieh PC, Koski TR, Ganju A, Ondra SL. Surgical treatment of fixed cervical kyphosis with myelopathy. Spine. $2008 \mathrm{Apr}$ 1;33(7):771-8

7. Scheer JK, Tang JA, Smith JS, Acosta FL, Jr., Protopsaltis TS, Blondel B, et al. Cervical spine alignment, sagittal deformity, and clinical implications A review. Journal of Neurosurgery-Spine. 2013 Aug;19(2):141-59.10.3171/2013.4.spine12838 8. Takeshita K, Murakami M, Kobayashi A, Nakamura C. Relationship between cervical curvature index (Ishihara) and cervical spine angle (C2--7). Journal of orthopaedic science : official journal of the Japanese Orthopaedic Association. 2001 2001;6(3):223-6.10.1007/s007760100038

9. Emery SE. Cervical spondylotic myelopathy: diagnosis and treatment. Journal of the American Academy of Orthopaedic Surgeons. 2001;9(6):376-88

10. Edwards CC, Riew KD, Anderson PA, Hilibrand AS, Vaccaro AF. Cervical myelopathy: current diagnostic and treatment strategies. The Spine Journal. 2003;3(1):68-81

11. Harrison DE, Harrison DD, Cailliet R, Troyanovich SJ, Janik TJ, Holland B. Cobb method or Harrison posterior tangent method: which to choose for lateral cervical radiographic analysis. Spine. 2000;25(16):2072-8

12. Hardacker JW, Shuford RF, Capicotto PN, Pryor PW. Radiographic standing cervical segmental alignment in adult volunteers without neck symptoms. Spine. 1997;22(13):1472-9

13. Bland JM, Altman D. Statistical methods for assessing agreement between two methods of clinical measurement. The lancet. 1986;327(8476):307-10 14. Critchley LA, Critchley JA. A meta-analysis of studies using bias and precision statistics to compare 
cardiac output measurement techniques. Journal of clinical monitoring and computing. 1999;15(2):85-91 15. Altman DG. Practical statistics for medical research: CRC Press; 1990.

16. Bland J, Altman D. A note on the use of the intraclass correlation coefficient in the evaluation of agreement between two methods of measurement. Computers in biology and medicine.

1990;20(5):337-40

17. Brennan P, Silman A. Statistical methods for assessing observer variability in clinical measures.

BMJ: British Medical Journal. 1992;304(6840):1491

18. Li G, Passias P, Kozanek M, Shannon BD, Li

GA, Villamil F, et al. Interobserver reliability and intraobserver reproducibility of powers ratio for assessment of atlanto-occipital junction: comparison of plain radiography and computed tomography. European Spine Journal. 2009 Apr;18(4):577-82.10.1007/ s00586-008-0877-5

19. Wang $Y$, Videman $T$, Niemelainen R, Battie MC. Quantitative Measures of Modic Changes in Lumbar Spine Magnetic Resonance Imaging. Spine. 2011 Jul;36(15):1236-43.10.1097/

BRS.0b013e3181ecf283

20. Blondel B, Parratte S, Tropiano P, Pauly V, Aubaniac JM, Argenson JN. Pelvic tilt measurement before and after total hip arthroplasty. Orthop Traumatol-Surg Res. 2009

Dec;95(8):568-72.10.1016/j.otsr.2009.08.004

21. Fleiss JL, Levin B, Paik MC. Statistical methods for rates and proportions: John Wiley \& Sons; 2013.

22. Klineberg E. Cervical spondylotic myelopathy: a review of the evidence. Orthop Clin North Am. 2010 Apr;41(2):193-202. Epub 2010/04/20.10.1016/ j.ocl.2009.12.010

23. Brain WR, Northfield $D$, Wilkinson $M$. The neurological manifestations of cervical spondylosis. Brain. 1952 Jun;75(2):187-225. Epub 1952/06/01 24. Payne EE, Spillane JD. The cervical spine; an anatomico-pathological study of 70 specimens (using a special technique) with particular reference to the problem of cervical spondylosis. Brain. 1957

Dec;80(4):571-96. Epub 1957/12/01

25. Lees F, Turner JW. NATURAL HISTORY AND PROGNOSIS OF CERVICAL SPONDYLOSIS. Br Med J. 1963 Dec 28;2(5373):1607-10. Epub 1963/12/28
26. Clarke E, ROBINSON PK. Cervical myelopathy: a complication of cervical spondylosis. Brain. 1956;79(3):483-510

27. Jinkins JR, Dworkin JS, Damadian RV. Upright, weight-bearing, dynamic-kinetic MRI of the spine: initial results. European radiology.

2005;15(9):1815-25

28. Jiang L, Qiu Y, Xu LL, Liu Z, Wang Z, Sha SF, et al. Sagittal spinopelvic alignment in adolescents associated with Scheuermann's kyphosis: a comparison with normal population. European Spine Journal. 2014 Jul;23(7):1420-6.10.1007/ s00586-014-3266-2

29. Vidal C, Ilharreborde B, Azoulay R, Sebag G, Mazda K. Reliability of cervical lordosis and global sagittal spinal balance measurements in adolescent idiopathic scoliosis. European Spine Journal. 2013 Jun;22(6):1362-7.10.1007/s00586-013-2752-2 30. Abumi K, Shono Y, Taneichi H, Ito M, Kaneda K. Correction of Cervical Kyphosis Using Pedicle Screw Fixation Systems. Spine. 1999 Nov 15;24(22):2389.10.1097/00007632-199911150-00017 31. Loder RT. The sagittal profile of the cervical and lumbosacral spine in Scheuermann thoracic kyphosis. Journal of Spinal Disorders. 2001

Jun;14(3):226-31.10.1097/ 00002517-200106000-00007

32. Roussouly P, Pinheiro-Franco JL. Biomechanical analysis of the spino-pelvic organization and adaptation in pathology. European spine journal : official publication of the European Spine Society, the European Spinal Deformity Society, and the European Section of the Cervical Spine Research Society. 2011 2011-Sep;20 Suppl 5:609-18.10.1007/ s00586-011-1928-x 33. Zdeblick TA, Bohlman H. Cervical kyphosis and myelopathy. Treatment by anterior corpectomy and strut-grafting. The Journal of Bone $\&$ Joint Surgery. 1989;71(2):170-82.

34. EMERY SE, BOHLMAN HH, BOLESTA MJ, JONES PK. Anterior Cervical Decompression and Arthrodesis for the Treatment of Cervical Spondylotic Myelopathy. Two to Seventeen-Year Followup*. The Journal of Bone \& Joint Surgery. 1998;80(7):941-51.

35. Uchida K, Nakajima H, Sato R, Yayama T, Mwaka ES, Kobayashi S, et al. Cervical spondylotic 
myelopathy associated with kyphosis or sagittal sigmoid alignment: outcome after anterior or posterior decompression: Clinical article. Journal of Neurosurgery: Spine. 2009;11(5):521-8

36. Gallie W. Fractures and dislocations of the cervical spine. The American Journal of Surgery. 1939;46(3):495-9

37. PEARCY M, Portek I, SHEPHERD J. Threedimensional $\mathrm{x}$-ray analysis of normal movement in the lumbar spine. Spine. 1984;9(3):294-7

38. Dupuis PR, Yong-Hing K, Cassidy JD, Kirkaldy-Willis WH. Radiologic diagnosis of degenerative lumbar spinal instability. Spine.

1985;10(3):262-76

39. Harrison DE, Haas JW, Cailliet R, Harrison DD, Holland B, Janik TJ. Concurrent validity of flexicurve instrument measurements: Sagittal skin contour of the cervical spine compared with lateral cervical radiographic measurements. Journal of Manipulative and Physiological Therapeutics. 2005 Oct;28(8):597-603.10.1016/j.jmpt.2005.08.012 40. Harrison DE, Harrison DD, Cailliet R, Troyanovich SJ, Janik TJ, Holland B. Cobb method or Harrison posterior tangent method: which to choose for lateral cervical radiographic analysis. Spine (Phila Pa 1976). 2000 Aug 15;25(16):2072-8. Epub 2000/ $08 / 23$

41. Polly DW, Jr., Kilkelly FX, McHale KA, Asplund LM, Mulligan M, Chang AS. Measurement of lumbar lordosis. Evaluation of intraobserver, interobserver, and technique variability. Spine (Phila $\mathrm{Pa}$ 1976). 1996 Jul 1;21(13):1530-5; discussion 5-6. Epub 1996/07/01

42. Singer KP, Jones TJ, Breidahl PD. A comparison of radiographic and computer-assisted measurements of thoracic and thoracolumbar sagittal curvature. Skeletal Radiol. 1990;19(1):21-6. Epub 1990/
$01 / 01$

43. Du W, Wang L, Shen Y, Zhang Y, Ding W, Ren L. Long-term impacts of different posterior operations on curvature, neurological recovery and axial symptoms for multilevel cervical degenerative myelopathy. European Spine Journal.

2013;22(7):1594-602

44. Du W, Zhang P, Shen Y, Zhang Y-z, Ding W-y, Ren L-x. Enlarged laminectomy and lateral mass screw fixation for multilevel cervical degenerative myelopathy associated with kyphosis. Spine Journal. 2014 Jan;14(1):57-64.10.1016/j.spinee.2013.06.017 45. Uribe JS, Sangala JR, Duckworth EAM, Vale FL. Comparison between anterior cervical discectomy fusion and cervical corpectomy fusion using titanium cages for reconstruction: analysis of outcome and long-term follow-up. European Spine Journal. 2009 May;18(5):654-62.10.1007/s00586-009-0897-9

\section{Disclosures \& COI}

The authors report no relevant financial disclosures or conflicts of interest.

\section{Corresponding Author}

Douglas S. Weinberg, MD, Department of Orthopaedic Surgery, Case Western Reserve University, 11100 Euclid Avenue, HH 5043, Cleveland, OH 44106. Dsw56@case.edu.

Published 7 September 2016. This manuscript is generously published free of charge by ISASS, the International Society for the Advancement of Spine Surgery. Copyright @ 2016 ISASS. To see more or order reprints or permissions, see http://ijssurgery.com. 